\title{
Effect of stress relaxation on distortion in additive manufacturing
}

\author{
process modeling \\ Erik R. Denlinger ${ }^{*}$ Pan Michaleris ${ }^{\dagger}$
}

June 9,2016

Keywords: LDED, Distortion, Residual Stress, FEM

\begin{abstract}
A method for modeling the effect of stress relaxation at high temperatures during Laser Direct Energy Deposition processes is experimentally validated for Ti-6Al-4V samples subject to different inter-layer dwell times. The predicted mechanical responses are compared to those of Inconel ${ }^{\circledR} 625$ samples, which experience no allotropic phase transformation, deposited under identical process conditions. The thermal response of workpieces in additive manufacturing is known to be strongly dependent on dwell time. In this work the dwell times used vary from 0 to $40 \mathrm{~s}$. Based on past research on ferretic steels and the additive manufacturing of titanium alloys it is assumed that the effect of transformation strain in Ti$6 \mathrm{Al}-4 \mathrm{~V}$ acts to oppose all other strain components, effectively eliminating all residual stress at temperatures above $690^{\circ} \mathrm{C}$. The model predicts that Inconel ${ }^{\circledR} 625$ exhibits increasing distortion with decreasing dwell times but that Ti-6Al-4V displays the opposite behavior, with distortion dramatically decreasing with lowering dwell time. These predictions are accurate when compared
\end{abstract}

\footnotetext{
${ }^{*}$ Research and Development, Pan Computing LLC

${ }^{\dagger}$ President, Pan Computing LLC, State College, PA 16803, USA, Email: pan.michaleris@pancomputing.com, Professor, Dept. of Mechanical and Nuclear Engineering, The Pennsylvania State University 
with experimental in situ and post-process measurements.

\section{Introduction}

Laser directed energy deposition (LDED) is a frequently used additive manufacturing (AM) process. The system allows for parts to be built up by adding metal layer-by-layer rather than subtracting material through the application of typical machining techniques. This leads to increased flexibility in manufacturing which can in turn reduce costs. The process is also useful for the repair and modification of existing parts. Unfortunately AM processes result in large thermal gradients in the workpiece, causing the emergence of residual stresses and distortion. Finite element modeling (FEM) can be used to predict distortion and residual stress levels, allowing for optimization of the build plan prior to part manufacture and thus avoiding costly trial and error iterations. Residual stresses are caused by either plasticity due to contraction of the weld region or by solid-state phase transformations present in the material [1]. To accurately predict distortion and residual stress present in a workpiece, a model should account for both.

Modeling of $\mathrm{AM}$ has primarily focused on predicting thermal response [2-7], predicting distortion and residual stress, [8-12], and developing distortion mitigation techniques [13, 14]. Several researchers have performed thorough model validations using in situ experimental measurement techniques $[3,9,10,15,16]$.

The use of FEM to predict distortion and residual stress in AM originates from the prior research performed on multi-pass welding. The inclusion of transformation strains caused by solidstate phase transformation present in steels has been shown to be critical in weld modeling due to the fact that transformation strains influence bulk distortion and residual stress of workpieces, with lower martensite-start temperature yielding reduced levels of residual stress and distortion $[17,18]$. Francis et al. have written a thorough review of welding residual stress present in steel and note 

the thermal contraction of the weld region [19]. The offsetting of strain attributable to thermal contraction by transformation strains alters the bulk residual stress distribution throughout a workpiece and has been shown to reduce bending stresses on the bottom of surface of base plates for bead-on-plate welds [20]. Because AM is a similar process to welding, the welding literature suggests that transformation strains also need to be included in AM models.

While the effect of transformation strains in steel is now well understood due to the prevalent use of the material in welding, the effect of transformation strains in Ti-6Al-4V, a material commonly used in AM, has not been extensively studied. Unlike steel which transforms from a FCC structure to a BCC structure upon cooling, two phase $(\alpha+\beta)$ Ti-6Al-4V undergoes an allotropic transformation from a BCC to a HCP structure. However, similarly to steel, the difference in coefficient of thermal expansion, volume, and hardness of the two Ti-6Al-4V phases alters the stress stress state of the material [21]. The effect of the stress relaxation on in situ distortion and residual stress in laser deposited $\mathrm{Ti}-6 \mathrm{Al}-4 \mathrm{~V}$ has been experimentally investigated, by comparing the mechanical responses of Ti-6Al-4V workpieces to the response of Inconel ${ }^{\circledR} 625$, a material that does not undergo an allotropic phase change [22]. Inter-layer dwell times were varied as previous work by Costa et al. concluded that microstructure was highly dependent on dwell times [23]. Shorter dwell times in the Ti-6Al-4V builds, which cause higher in-process temperatures to be reached and thus greater transformation to the $\beta$ phase, were shown to result in dramatically relax levels of distortion and residual stress, a trend not seen in the Inconel ${ }^{\circledR} 625$ builds. The results indicate that the transformations strains oppose the strain attributed to the contraction of the molten material, similar to what has been observed in steel, causing a relaxation of the residual stress. Currently no model presented in the literature has been validated to capture this effect for LDED processing.

This work serves to validate a method for introducing the effect of stress relaxation present 
in Ti-6Al-4V into FE models of LDED. First, a transient thermal model is validated against in situ temperature measurements taken during the deposition of 42 layer high, three pass wide, Ti$6 \mathrm{Al}-4 \mathrm{~V}$ and Inconel ${ }^{\circledR} 625$ wall builds with varying inter-layer dwell times. Ti-6Al-4V is chosen due to the fact that it undergoes a solid-state phase transformation. Inconel ${ }^{\circledR} 625$ should be possible to accurately model without the inclusion of transformation strains, as it does not undergo a solid-state phase transformation. Next, the constitutive model neglecting transformation strains is used to model the mechanical responses of the materials and compared with experimental in situ distortion measurements and post-process residual stress measurements. The Ti-6Al-4V builds are then simulated while accounting for the transformation strains to investigate if improved correlation with experiment is achieved.

\section{Modeling Approach}

The thermal history is first calculated by performing a three-dimensional transient thermal analysis. The thermal results are then input into a three-dimensional quasi-static incremental analysis which simulates the mechanical response. The thermal analysis can be performed independently of the mechanical analysis because the plastic strain energy is small compared to the laser source energy, making the analyses weakly coupled [24]. A detailed description of the model is available in reference [16].

\subsection{Transient Thermal Analysis}

The governing transient heat transfer energy balance in the entire volume of the material is given as:

$$
\rho C_{p} \frac{d T}{d t}=-\nabla \cdot \boldsymbol{q}(\boldsymbol{r}, t)+Q(\boldsymbol{r}, t)
$$


where $\rho$ is the material density, $C_{p}$ is the specific heat capacity, $T$ is the temperature, $t$ is the time, $Q$ is the internal heat generation rate, $\boldsymbol{r}$ is the relative reference coordinate, and $\boldsymbol{q}$ is the heat flux. The Fourier heat flux constitutive relation is given by:

$$
\boldsymbol{q}=-k \nabla T
$$

dependent on temperature dependent thermal conductivity $k$.

Thermal radiation $q_{\text {rad }}$ is accounted for using the Stefan-Boltzmann law:

$$
q_{\text {rad }}=\varepsilon \sigma\left(T_{s}^{4}-T_{\infty}^{4}\right)
$$

where $\varepsilon$ is the surface emissivity, $\sigma$ is the Stefan-Boltzmann constant, $T_{s}$ is the surface temperature of the workpiece, and $T_{\infty}$ is the ambient temperature.

Newton's law of cooling describes the heat loss due to convection $q_{c o n v}$ :

$$
q_{\text {conv }}=h\left(T_{s}-T_{\infty}\right)
$$

where $h$ is the convective heat transfer coefficient.

\subsection{Mechanical Analysis}

The governing mechanical stress $\boldsymbol{\sigma}$ equilibrium equation is written as:

$$
\nabla \cdot \boldsymbol{\sigma}=\mathbf{0}
$$

The mechanical constitutive law is:

$$
\boldsymbol{\sigma}=\mathbf{C} \epsilon_{\mathrm{e}}
$$

Total strain $\boldsymbol{\epsilon}$, assuming small deformation thermo-elasto-plasticity, is decomposed as:

$$
\boldsymbol{\epsilon}=\boldsymbol{\epsilon}_{\mathrm{e}}+\boldsymbol{\epsilon}_{\mathrm{p}}+\boldsymbol{\epsilon}_{\mathrm{T}}+\boldsymbol{\epsilon}_{\mathrm{t}}
$$


where $\mathbf{C}$ is the fourth order material stiffness tensor, and $\boldsymbol{\epsilon}_{\mathrm{e}}, \boldsymbol{\epsilon}_{\mathrm{p}}, \boldsymbol{\epsilon}_{\mathrm{T}}$, and $\boldsymbol{\epsilon}_{\mathrm{t}}$ are the elastic, plastic, thermal, and transformation strain, respectively. The thermal strain is computed as:

$$
\begin{aligned}
\boldsymbol{\epsilon}_{\mathrm{T}} & =\boldsymbol{\epsilon}_{\mathrm{T}} \boldsymbol{j} \\
\boldsymbol{\epsilon}_{\mathrm{T}} & =\boldsymbol{\alpha}\left(T-T^{r e f}\right) \\
\boldsymbol{j} & =\left[\begin{array}{llllll}
1 & 1 & 1 & 0 & 0 & 0
\end{array}\right]^{T}
\end{aligned}
$$

where $\boldsymbol{\alpha}$ is the thermal expansion coefficient and $T^{r e f}$ is reference temperature. The plastic strain is computed by enforcing the von Mises yield criterion and the the Prandtl-Reuss flow rule:

$$
\begin{gathered}
f=\sigma_{m}-\sigma_{y}\left(\boldsymbol{\epsilon}_{\mathrm{q}}, T\right) \leq 0 \\
\dot{\boldsymbol{\epsilon}}_{\mathrm{p}}=\dot{\boldsymbol{\epsilon}}_{\mathrm{q}} \boldsymbol{a} \\
\boldsymbol{a}=\left(\frac{\partial f}{\partial \boldsymbol{\sigma}}\right)^{T}
\end{gathered}
$$

where $f$ is the yield function, $\sigma_{m}$ is Mises' stress, $\sigma_{Y}$ yield stress, $\boldsymbol{\epsilon}_{\mathrm{q}}$ is the equivalent plastic strain, and $\boldsymbol{a}$ is the flow vector.

For an incremental formulation, Equation (6) is re-written as:

$$
{ }^{n} \boldsymbol{\sigma}={ }^{n-1} \boldsymbol{\sigma}+\Delta \boldsymbol{\sigma}
$$

where ${ }^{n-1} \boldsymbol{\sigma}$ and ${ }^{n} \boldsymbol{\sigma}$ are the stress at the previous and current increment. The stress increment $\Delta \sigma$ is computed as:

$$
\Delta \boldsymbol{\sigma}=\Delta \mathbf{C}\left({ }^{n-1} \boldsymbol{\epsilon}-{ }^{n-1} \boldsymbol{\epsilon}_{\mathrm{p}}-{ }^{n-1} \boldsymbol{\epsilon}_{\mathrm{T}}-{ }^{n-1} \boldsymbol{\epsilon}_{\mathrm{t}}\right)+\mathbf{C}\left(\Delta \boldsymbol{\epsilon}-\Delta \boldsymbol{\epsilon}_{\mathrm{p}}-\Delta \boldsymbol{\epsilon}_{\mathrm{T}}-\Delta \boldsymbol{\epsilon}_{\mathrm{t}}\right)
$$

where left superscripts denote the time increment where a quantity is computed and $\Delta \boldsymbol{\epsilon}$ is the total strain increment corresponding to the current displacement increment. 


\section{Experimental Validation}

The modeling approach laid out in Section two is applied to simulate the experimental results for Ti-6Al-4V and Inconel ${ }^{\circledR} 625$ wall builds from reference $[22]$ in an attempt to capture the mechanical responses reported. A brief overview of the experiment is provided here. 


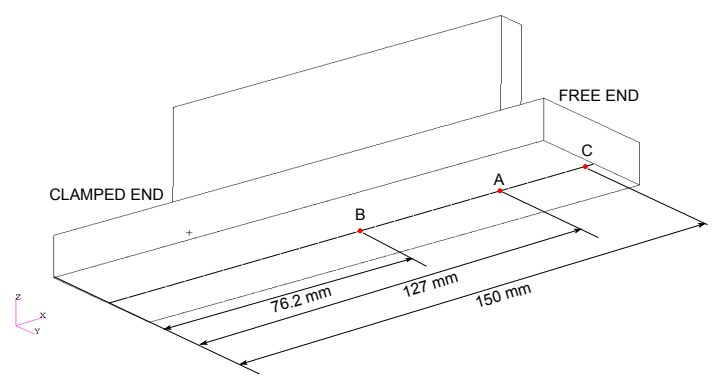

(a) Locations of the thermocouple 1 (A), thermocouple 2

(B), LDS (C), and blind hole drilling (B) measurements.

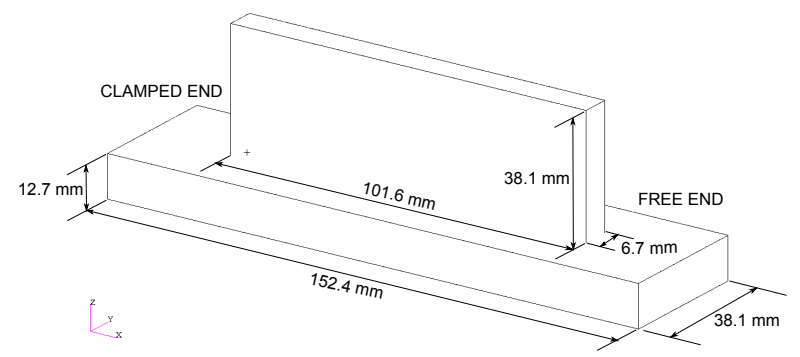

(b) Dimensions of the substrate and wall.

Figure 1: Illustration of the sample dimensions and measurement locations

Table 1: Description of the cases

\begin{tabular}{lcc}
\hline Case & Material & Dwell time (s) \\
\hline 1 & Inconel $^{\circledR} 625$ & 0 \\
2 & Inconel $^{\circledR} 625$ & 20 \\
3 & Inconel $^{\circledR} 625$ & 40 \\
4 & Ti-6Al-4V & 0 \\
5 & Ti-6Al-4V & 20 \\
6 & Ti-6Al-4V & 40 \\
\hline
\end{tabular}


In addition to the in situ distortion and temperature measurements, residual stress measurement were taken post-process. The hole drilling method was used to take a stress measurement on the substrate of each sample. Figure 1(a) shows the measurement location. The hole drilling method has an accuracy of $\pm 50 \mathrm{MPa}$.

\section{Numerical Implementation}

Figure 2 displays the three-dimensional finite element mesh, generated in Patran 2012 by MSC, used for both the thermal and mechanical analyses. The same mesh is used for all cases. The mesh contains 52,472 Hex-8 elements and 62,231 nodes. Hex-8 elements were chosen because they have been shown to yield more accurate results than tetrahedral elements when plastic deformation occurs [26]. The elements for the deposited material are allotted as two per laser spot size radius and 1 per deposition thickness, making the elements $1 \times 1 \times 0.87 \mathrm{~mm}^{3}$ in volume. The mesh is coarsened as it moves away from the deposition. A three-step mesh convergence study was performed to confirm the suitability of the mesh, and to insure that inaccuracy did not arise due to shear locking. The mesh used contains elements with aspect ratios of 3.175. Each mesh used in the convergence study varied the aspect rationThe fixture clamp is included in the model to capture heat loss through conduction.

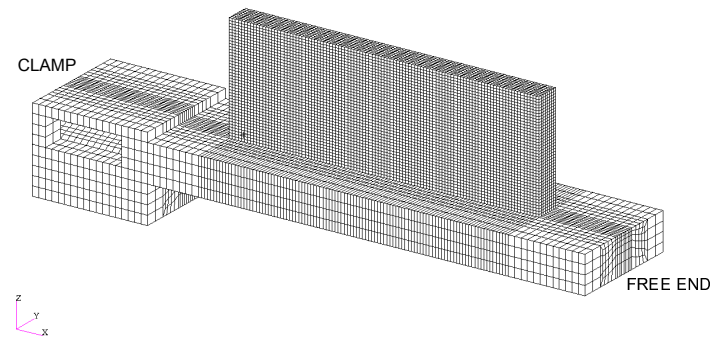

Figure 2: Finite element mesh used for all simulations. 


\subsection{Solution Method}

The thermal and mechanical analyses are performed using the code CUBES ${ }^{\circledR}$ by Pan Computing LLC. The analyses are performed in a series of time steps with the current time step taking the solution at the previous time step as an initial condition. Each time step moves the heat source a distance equal to its radius. At each time step the discrete equilibrium equations are solved using the Newton-Raphson method.

The temperature dependent material properties for Ti-6Al-4V and Inconel ${ }^{\circledR} 625$ are listed in Table 2. The properties between those listed are obtained by linear interpolation over the temperature range. Properties at temperatures above and below those listed are taken as the nearest tabulated value. Density is a constant $4.43 \times 10^{-6} \mathrm{~g} / \mathrm{mm}^{3}$ and $8.44 \times 10^{-6} \mathrm{~g} / \mathrm{mm}^{3}$ for Ti-6Al-4V and Inconel ${ }^{\circledR} 625$, respectively. The emissivity $\varepsilon$ of Inconel ${ }^{\circledR} 625$ is taken as 0.28 as found in reference [27]. The reference does state that the value is only an approximation, as the emissivity will vary with surface finish. The emissivity $\varepsilon$ of Ti-6Al- $4 \mathrm{~V}$ is set as 0.25 , as experimentally determined by Yang [28] for LDED processing of Ti-6Al-4V. The convective heat transfer coefficient $h$ is taken as $18 \mathrm{~W} / \mathrm{m}^{2} /{ }^{\circ} \mathrm{C}$ by correlating simulated and experimental results. 
Table 2: Temperature dependent thermal properties of Ti-6Al-4V [29] and Inconel ${ }^{\circledR} 625$ [30]

\begin{tabular}{lcccc}
\hline$T\left({ }^{\circ} \mathrm{C}\right)$ & $k\left(\mathrm{~W} / \mathrm{m} /{ }^{\circ} \mathrm{C}\right)$ & $C_{p}(\mathrm{~J} / \mathrm{kg})$ & $k\left(\mathrm{~W} / \mathrm{m} /{ }^{\circ} \mathrm{C}\right)$ & $C_{p}(\mathrm{~J} / \mathrm{kg})$ \\
\hline \multicolumn{4}{c}{ Ti-6Al-4V } & \multicolumn{2}{c}{ Inconel ${ }^{\circledR}$} & 625 \\
20 & 6.6 & 565 & 9.9 & 410 \\
93 & 7.3 & 565 & 10.8 & 427 \\
205 & 9.1 & 574 & 12.5 & 456 \\
315 & 10.6 & 603 & 14.1 & 481 \\
425 & 12.6 & 649 & 15.7 & 511 \\
540 & 14.6 & 699 & 17.5 & 536 \\
650 & 17.5 & 770 & 19.0 & 565 \\
760 & 17.5 & 858 & 20.8 & 590 \\
870 & 17.5 & 959 & 22.8 & 620 \\
982 & - & - & 25.2 & 645 \\
\hline
\end{tabular}

The temperature dependent mechanical properties for Ti-6Al-4V and Inconel 625 , listed in Table 3, include the elastic modulus $E$, yield strength $\sigma_{y}$, and the coefficient of thermal expansion $\alpha$. 
Table 3: Temperature dependent mechanical properties of Ti-6Al-4V $[8,29]$ and Inconel ${ }^{\circledR} 625[30]$

\begin{tabular}{lcccccc}
\hline$T\left({ }^{\circ} \mathrm{C}\right)$ & $E(\mathrm{GPa})$ & $\sigma_{y}(\mathrm{MPa})$ & $\alpha\left(\mu \mathrm{m} / \mathrm{m}{ }^{\circ} \mathrm{C}\right)$ & $E(\mathrm{GPa})$ & $\sigma_{y}(\mathrm{MPa})$ & $\alpha$ \\
\hline \multicolumn{5}{c}{$\mathrm{Ti}-6 \mathrm{Al}-4 \mathrm{~V}$} & \multicolumn{3}{c}{ Inconel $^{\circledR} 625$} \\
20 & 104 & 768 & 8.60 & 208 & 493 & 12.8 \\
93 & 101 & 735 & 8.66 & 204 & 479 & 12.8 \\
205 & 94.0 & 685 & 8.75 & 198 & 443 & 13.1 \\
315 & 88.3 & 636 & 9.08 & 192 & 430 & 13.3 \\
425 & 82.6 & 586 & 9.40 & 186 & 424 & 13.7 \\
540 & 77.5 & 542 & 9.55 & 179 & 423 & 14.0 \\
650 & 72.6 & 501 & 9.70 & 170 & 422 & 14.8 \\
760 & 67.7 & 459 & 9.70 & 161 & 415 & 15.3 \\
870 & 62.8 & 417 & 9.70 & 148 & 386 & 15.8 \\
927 & - & - & - & - & - & 16.2 \\
\hline
\end{tabular}

\subsection{Boundary Conditions}

Convection and radiation are applied to all free surfaces of the mesh. The model substrate is mechanically constrained as cantilevered to represent the experimental conditions. The laser heat source is modeled using the Goldak double ellipsoid model [25] as follows:

$$
Q=\frac{6 \sqrt{3} P \eta}{a b c \pi \sqrt{\pi}} e^{-\left[\frac{3 x^{2}}{a^{2}}+\frac{3 y^{2}}{b^{2}}+\frac{3(z+v t)^{2}}{c^{2}}\right]}
$$

where $P$ is the incident laser power, $\eta$ is the absorbtion efficiency; $x, y$, and $z$ are the local coordinates; $a, b$, and $c$ are the transverse, depth, and longitudinal dimension of the ellipsoid respectively, $v$ is the scan speed, and $t$ is the time. 


\subsection{Material Deposition Modeling}

A hybrid quiet-inactive element approach is used to simulate the addition of deposited material. The method was proposed in reference [31]. At the start of the simulation all deposited elements are inactive, i.e., not part of the analysis. The elements are switched to quiet, meaning that they are given properties such that they do not affect the analysis, on a layer-by-layer basis. A quiet element is made active when the following condition is met at any Gauss point of the element [31]:

$$
\frac{6 \sqrt{3}}{a b c \pi \sqrt{\pi}} e^{-\left[\frac{3 x^{2}}{a^{2}}+\frac{3 y^{2}}{b^{2}}+\frac{3(z+v t)^{2}}{c^{2}}\right]} \geq 0.05
$$

Both surface radiation and convection are applied as a boundary condition to the evolving interface between quiet and active elements, which is identified at each time increment.

\section{Modeling results and comparison to the experiment}

\subsection{Thermal History}

The thermal response of the workpiece is calculated by the model and compared to the experimental measurements. Figure 3 shows the experimental results, as measured by thermocouples 1 and 2, compared to calculated results at nodes corresponding to the thermocouple locations for each case. Reference [22] notes that because thermocouple 1 and 2 are at different locations on the substrate, they record different thermal histories. Thermocouple 1, at the free end of the substrate, shows a lower peak temperature than thermocouple 2, at the middle of the substrate. Samples with the same dwell times display similar thermal histories independent of the sample material. For each case the sample temperatures increase for roughly the first third of the build and then begin to decrease due to the heat source moving vertically away from the thermocouple locations. Longer dwell times results in lower peak temperatures with the $40 \mathrm{~s}$ dwell cases (Case 3 and Case 6) 
exceeding $400^{\circ} \mathrm{C}$ and the $0 \mathrm{~s}$ dwell cases (Case 1 and Case 4 ) exceeding $600^{\circ} \mathrm{C}$.

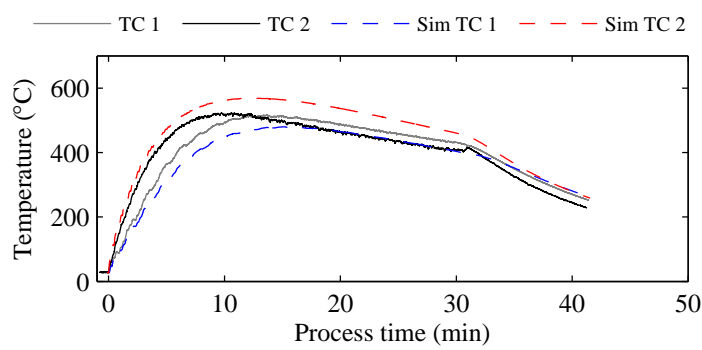

(a) Case 1: Inconel ${ }^{\circledR}$ 0s Dwell

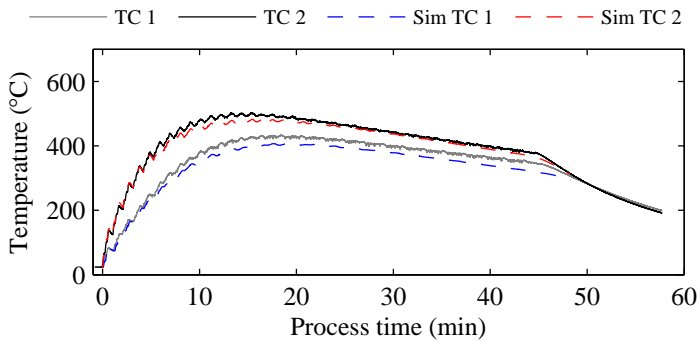

(c) Case 2: Inconel ${ }^{\circledR} 20$ s Dwell

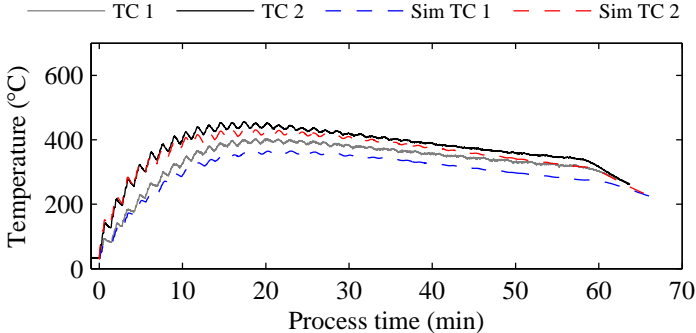

(e) Case 3: Inconel ${ }^{\circledR}$ 40s Dwell

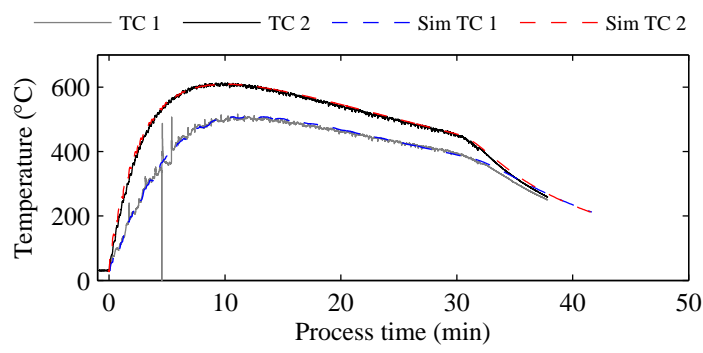

(b) Case 4: Ti64 0s Dwell

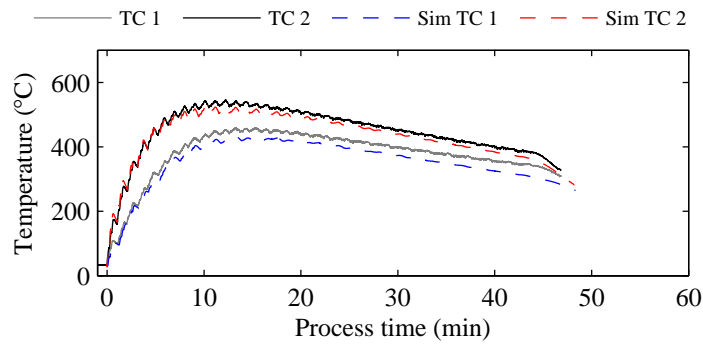

(d) Case 5: Ti64 20s Dwell

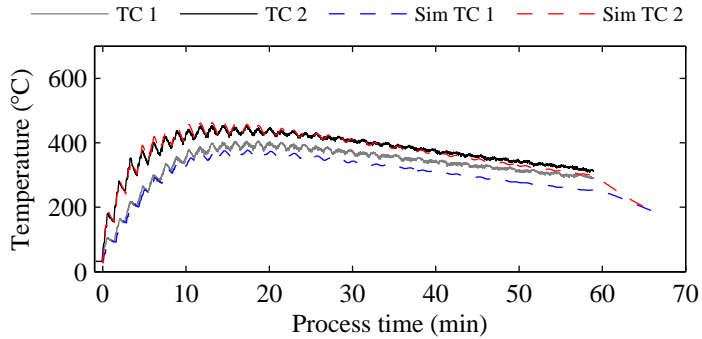

(f) Case 6: Ti64 40s Dwell

Figure 3: In situ thermal history of each thermocouple for all wall builds. (a) Case 1, (b) Case 4, (c) Case 2, (d) Case 5, (e) Case 3, (f) Case 6.

The results of the transient thermal analyses are in close agreement with the experimental results as can be seen in Figure 3. The average percent error for the entire simulation of each case can be calculated as 


$$
\% \text { Error }=\frac{100 \sum_{i=1}^{n}\left|\frac{\left(x_{e x p}\right)_{i}-\left(x_{\text {sim }}\right)_{i}}{\left(x_{e x p}\right)_{i}}\right|}{n}
$$

where $n$ is the total number of simulated time increments, $i$ is the current time increment, $x_{\text {sim }}$ is the simulated value, and $x_{\text {exp }}$ is the experimentally measured value. The largest error at any thermocouple is found to be $12.0 \%$. Table 4 shows the percent error at each thermocouple for all cases.

Table 4: Cases examined for thermal model calibration

\begin{tabular}{lcccc}
\hline Case & Material & Dwell time (s) & \% Error TC 1 & \% Error TC 2 \\
\hline 1 & Inconel $^{\circledR} 625$ & 0 & 7.45 & 12.0 \\
2 & Inconel $^{\circledR} 625$ & 20 & 6.37 & 3.24 \\
3 & Inconel $^{\circledR} 625$ & 40 & 9.65 & 4.46 \\
4 & Ti-6Al-4V & 0 & 2.20 & 1.48 \\
5 & Ti-6Al-4V & 20 & 7.12 & 3.85 \\
6 & Ti-6Al-4V & 40 & 9.14 & 3.14 \\
\hline
\end{tabular}

\subsection{Distortion History}

In situ distortion is calculated and compared to the experimental measurements of the distortion of $12.7 \mathrm{~mm}$ thick Inconel ${ }^{\circledR}$ and Ti-6Al4V substrates during laser deposition with dwell times ranging from 0 t0 40 s. Figure 4 shows the final calculated distortion of Inconel ${ }^{\circledR}$ wall deposited with no dwell time (Case 1). The distortion is caused by the shrinking of the deposited material upon cooling. The LDS monitors the in situ distortion of the free end of the substrate. The simulated in situ distortion is recorded at a node corresponding to the LDS measurement location in the model. 

Case 1.

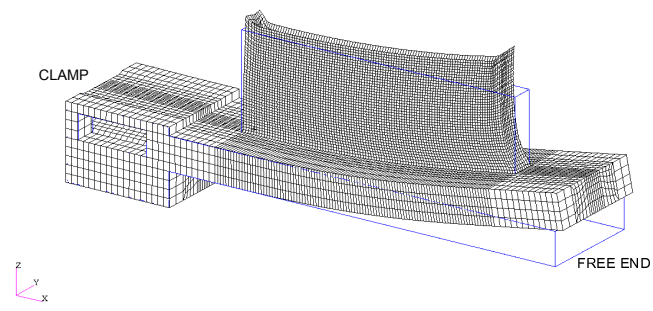

Figure 4: Mechanical model showing the final distorted shape of the workpiece (4 x magnification),

\subsubsection{Inconel $^{\circledR} 625$}

Figure 5 presents the measured and simulated distortion for the Inconel ${ }^{\circledR} 625$ builds with 0 (Case 1), 20 (Case 2), and $40 \mathrm{~s}$ (Case 3) dwell times. Periods of decreasing distortion are caused by the thermal expansion of the top of the substrate due to heating from the laser. An increase in distortion is attributable to the shrinking of the deposited material upon cooling. Each of the Inconel ${ }^{\circledR} 625$ experimental builds displays a consistent accumulation of distortion over the duration of the build which occurs independent of dwell time. The simulated distortion of the model captures these trends and is in close agreement with the experiment throughout the deposition for each case. 


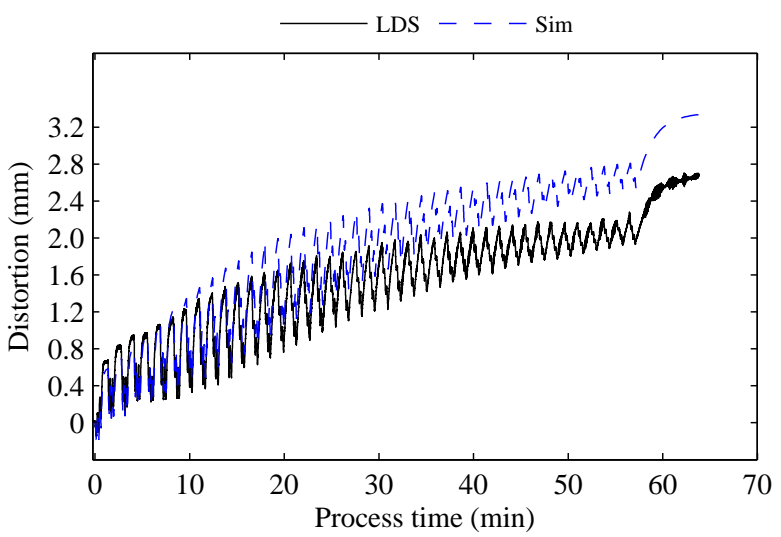

(a) Case 1: Inconel ${ }^{\circledR}$ 0s Dwell

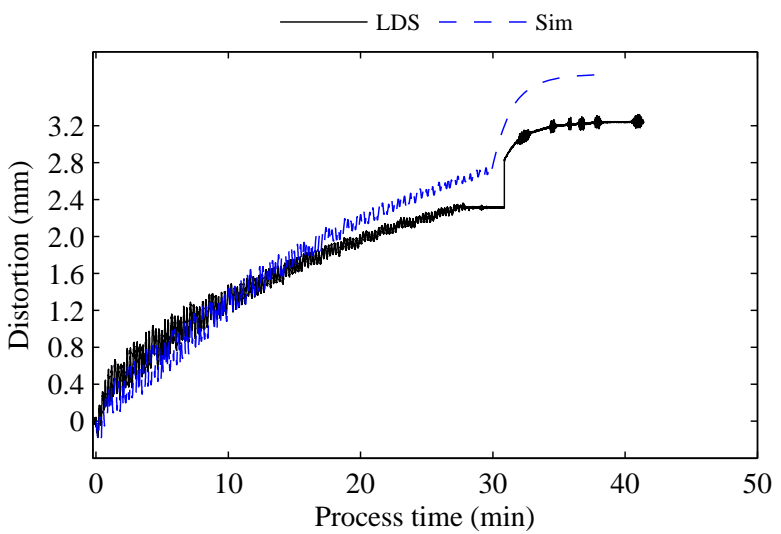

(b) Case 2: Inconel ${ }^{\circledR}$ 20s Dwell

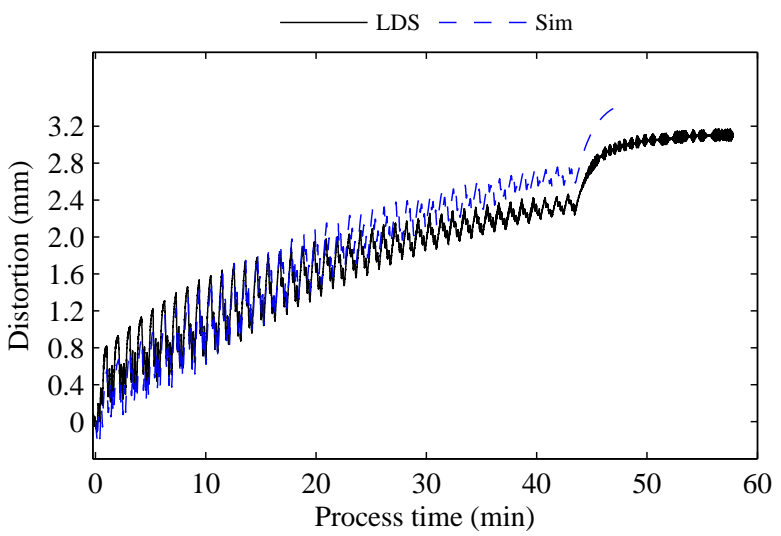

(c) Case 3: Inconel ${ }^{\circledR} 40$ s Dwell

Figure 5: Calculated in situ distortion results for the Inconel ${ }^{\circledR} 625$ samples compared with the experimental data. 


\subsubsection{Ti-6Al-4V}

Figure 6 shows the calculated distortion time trace for the Ti-6Al-4V samples, both with and without the inclusion of stress relaxation, compared with the experimental measurements for dwell times of 0 (Case 4), 20 (Case 5), and $40 \mathrm{~s}$ (Case 6). The simulations that employ the constitutive model with no transformation strain show distortion accumulating consistently throughout the deposition, similar to the trend seen in the Inconel ${ }^{\circledR}$ builds, but with significantly higher levels of distortion. This prediction is at odds with the experimental measurements which show significantly lower distortion levels in the Ti-6Al-4V builds when compared with the Inconel ${ }^{\circledR}$ builds. The fact that the model predicts a consistent accumulation of distortion with respect to time is also not in agreement with the measurements, which in the Case of the 0 and $20 \mathrm{~s}$ dwell cases show a reduction of distortion accumulation following the initial deposited layers. This reduction in distortion levels occurs due to the fact that the relaxation of residual stress, caused by the transformation strain negating the strain attributed to the contraction of the deposited material, manifests itself as a reduction in accumulated distortion [16].

In addition to not capturing the trend of distortion accumulation, the constitutive model neglecting transformation strain also significantly over predicts the final distortion of the workpiece. For example in Case 4 ( $0 \mathrm{~s}$ dwell), the calculated distortion of $6.39 \mathrm{~mm}$ over predicts the measured final distortion of $1.14 \mathrm{~mm}$ by $461 \%$. This percent error is similar to that reported in reference [16] when a constitutive model without stress relaxation was used to model the distortion of Ti-6Al-4V deposited by an electron beam.

Unlike the constitutive model that neglects transformation strain, the simulations using the constitutive model that includes the transformation strain term show that in the $0 \mathrm{~s}$ dwell case, Ti-6Al-4V does not consistently accumulate distortion over the duration of the build. The model actually registers a reduction of distortion after the initial layers, shown in Figure 7, followed by 
little accumulation over the rest of the build. This effect is lessened when adding a $20 \mathrm{~s}$ dwell time and is not present at all when a $40 \mathrm{~s}$ dwell is added, showing consistent distortion accumulation throughout the build. These predictions, showing a strong dependence of distortion on dwell time, are in close agreement with the experimental observations. 


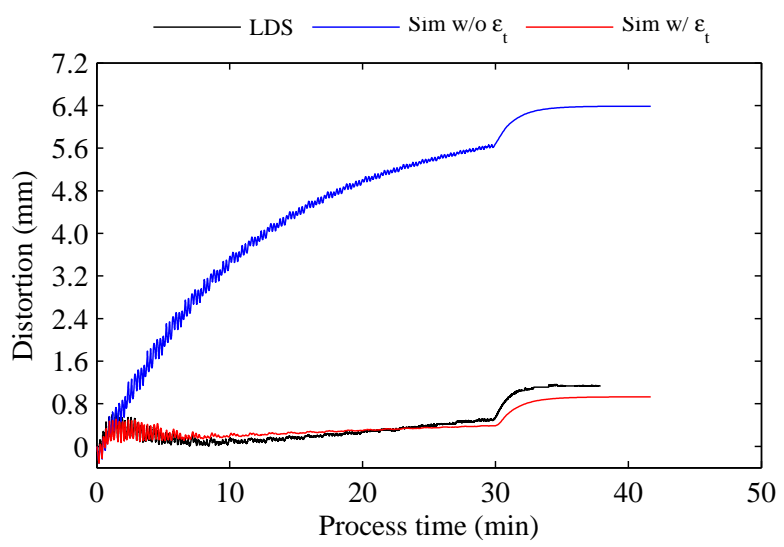

(a) Case 4: Ti-6Al-4V 0s Dwell

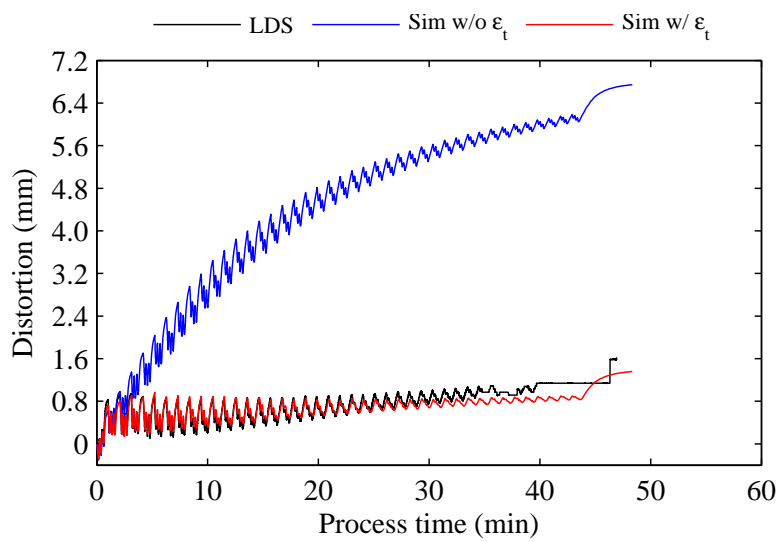

(b) Case 5: Ti-6Al-4V 20s Dwell

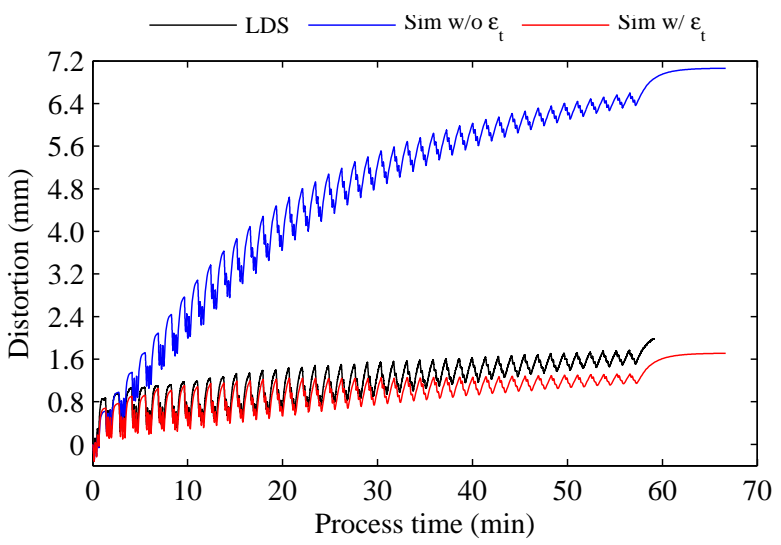

(c) Case 6: Ti-6Al-4V 40s Dwell

Figure 6: Calculated in situ distortion results for the Ti-6Al-4V samples compared with the experimental data. 


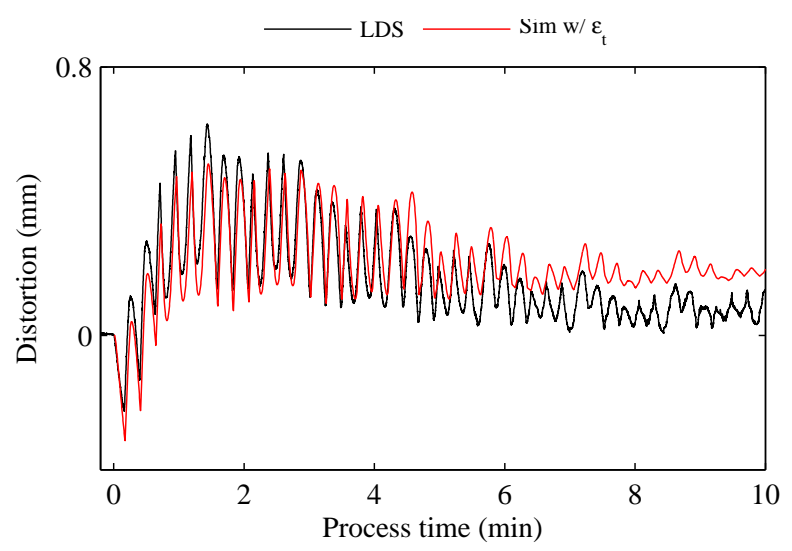

(a) Calculated in situ distortion results for Case 4 (Ti-6Al-

$4 \mathrm{~V} 0 \mathrm{~s}$ dwell time, compared with experiment for the first 15 deposition layers.

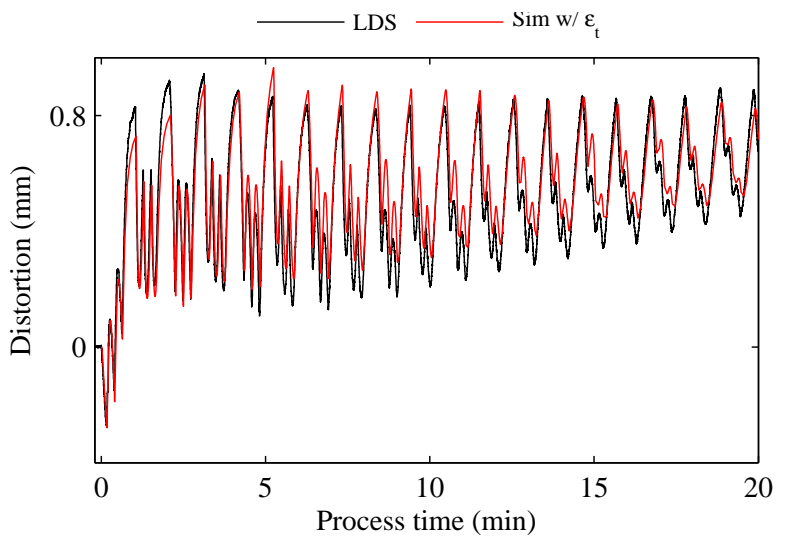

(b) Calculated in situ distortion results for Case 5 (Ti-6Al-

4V 20 s dwell time, compared with experiment for the first 15 deposition layers.

Figure 7: Calculated in situ distortion results for the Ti-6Al-4V samples compared with the experimental data showing the loss in accumulated distortion.

\subsection{Residual Stress}

Residual stress values are calculated for all time-steps during the simulation. The final calculated value for residual stress at the location of the blind hole drilling measurement is compared to the 
experimental measurement for the Inconel ${ }^{\circledR} 625$ and Ti-6Al-4V substrates with dwell times ranging from 0 to $40 \mathrm{~s}$. The longitudinal component of stress is chosen for comparison, as it is the dominate component.

\subsubsection{Inconel $^{\circledR} 625$}

The residual stress predictions from the model are compared with the results from the blind hole drilling experiments in Figure 8. The model predicts that residual stress in the Inconel ${ }^{\circledR} 625$ exhibits nearly no dependence on dwell time, showing a post-process residual stress of just over $500 \mathrm{MPa}$. The experiment shows decreasing residual stress with increasing dwell time, a trend not captured by the model likely due to the fact that temperature dependent precipitation hardening present in Inconel ${ }^{\circledR} 625$ is not included in the model. Figure 9 shows the calculated residual stress $\left(\sigma_{x x}\right)$ contour plots at the yz mid cross section.

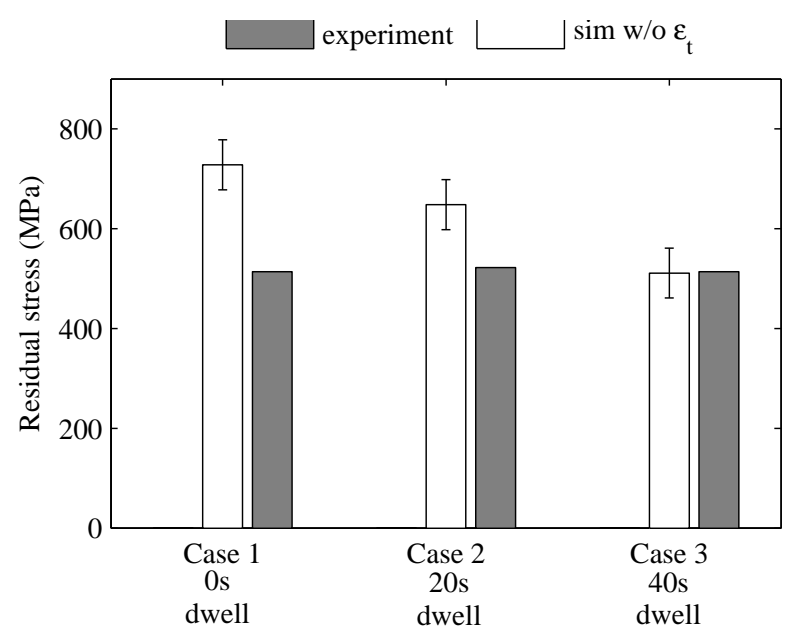

Figure 8: Calculated residual stress $\left(\sigma_{x x}\right)$ results for the Inconel ${ }^{\circledR} 625$ samples compared with the experimental data. 


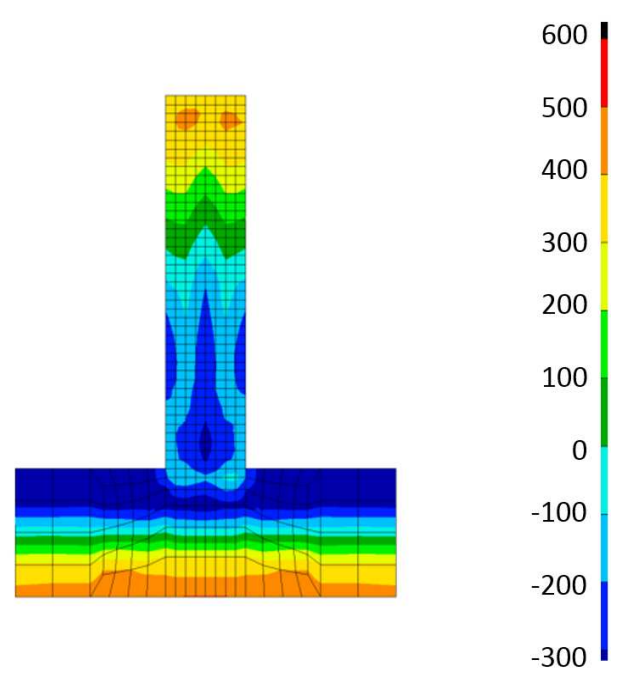

(a) Inconel ${ }^{\circledR} 6250 \mathrm{~s}$ dwell time.

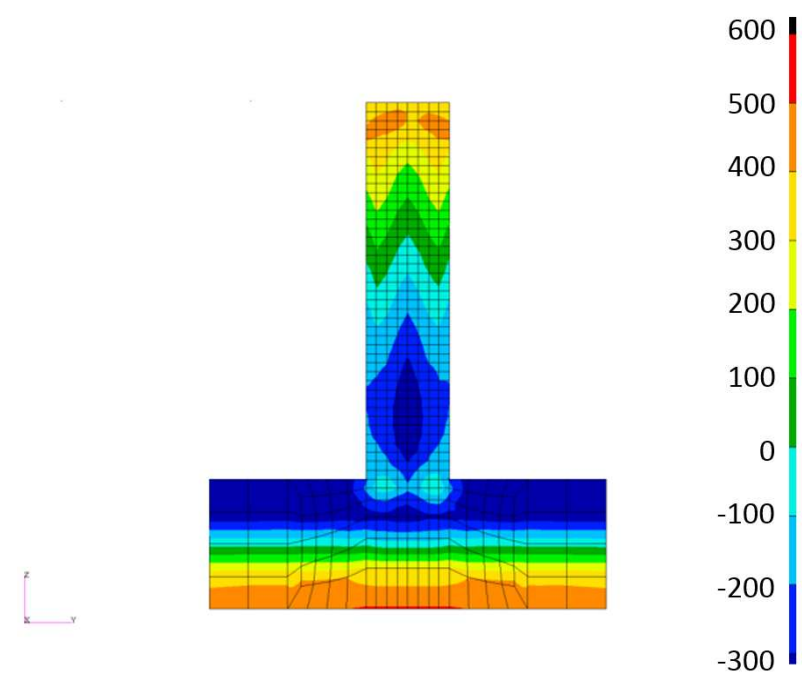

(b) Inconel ${ }^{\circledR} 40 \mathrm{~s}$ dwell time.

Figure 9: Calculated residual stress $\left(\sigma_{x x}\right)$ results at the mid yz cross section for the Inconel ${ }^{\circledR} 625$ samples.

\subsubsection{Ti-6Al-4V}

Figure 10 shows the residual stress results for the model when including transformation strain and neglecting transformation strain compared with the experimental measurements. The experimental 


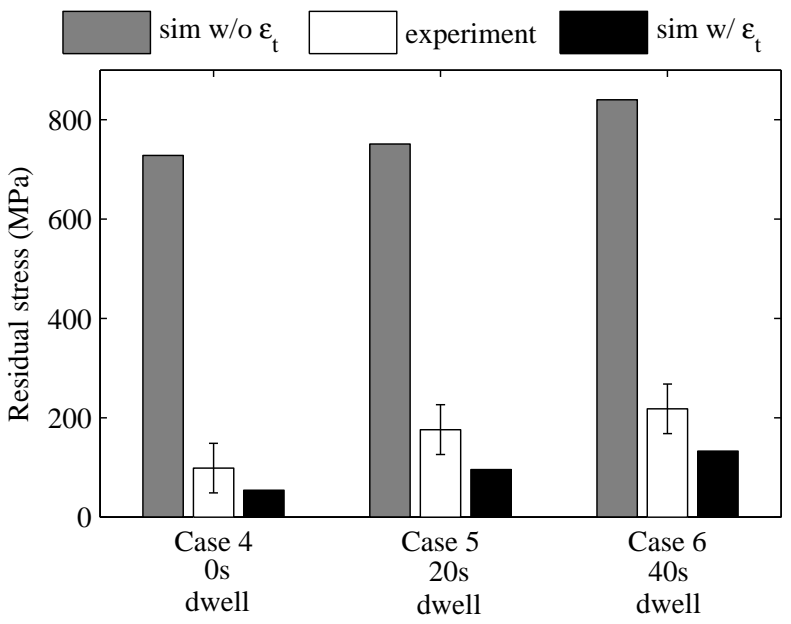

Figure 10: Calculated residual stress $\left(\sigma_{x x}\right)$ results for the Ti-6Al-4V samples compared with the experimental data. 


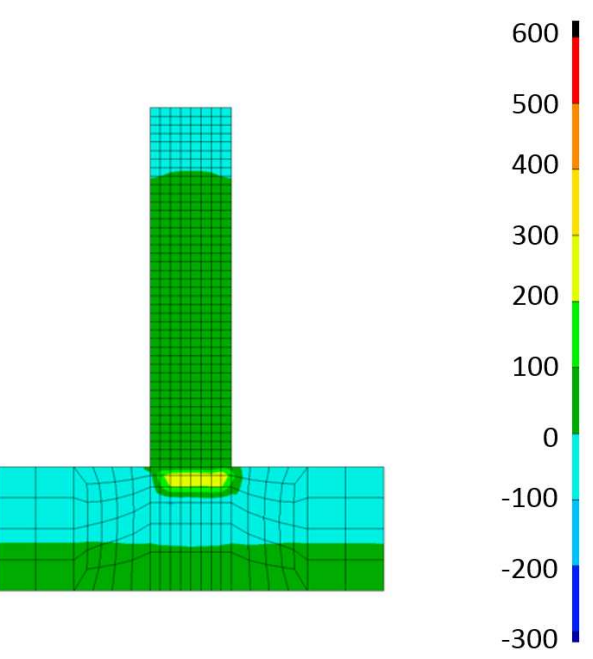

(a) Ti-6Al-4V 0 s dwell time.

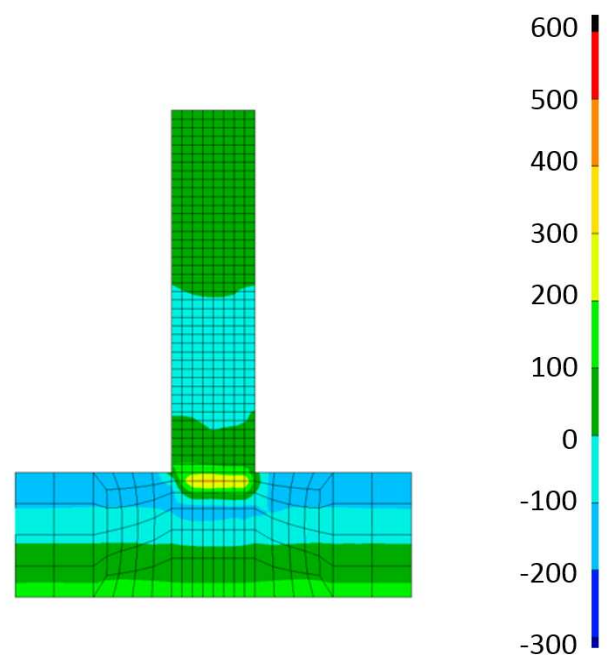

(b) Ti-6Al-4V 40 s dwell time.

Figure 11: Calculated residual stress $\left(\sigma_{x x}\right)$ results at the mid yz cross section for the Ti-6Al-4V samples.

\section{Conclusions}

Being able to predict the mechanical response of AM workpieces is important if expensive trial and error iterations are to be avoided. A model has been validated to adequately account for 


\section{Acknowledgements}

The authors would also like to acknowledge the partial support for this research by the Open Manufacturing program of the Defense Advanced Research Projects Agency and the Office of Naval Research through Grant N00014-12- 1-0840. Any opinions, findings, and conclusions or recommendations expressed in this material are those of the authors and do not necessarily reflect the views of the the Department of Defense or the US government. 


\section{References}

[1] Michaleris P. Minimization of welding distortion and buckling: Modelling and implementation. Elsevier; 2011.

[2] Kolossov S, Boillat E, Glardon R, Fischer P, Locher M. 3D FE simulation for temperature evolution in the selective laser sintering process. International Journal of Machine Tools and Manufacture. 2004;44(2):117-123.

[3] Peyre P, Aubry P, Fabbro R, et al. Analytical and numerical modelling of the direct metal deposition laser process. J Phys D: Appl Phys. 2008;41(2):025403.

[4] Qian L, Mei J, Liang J, et al. Influence of position and laser power on thermal history and microstructure of direct laser fabricated Ti-6Al-4V samples. Mater Sci Technol. 2005;21(5):597-605.

[5] Shen N, Chou K. Thermal Modeling of Electron Beam Additive Manufacturing ProcessPowder Sintering Effects. In: Proc. ASME 2012 Int Manuf Sci and Eng Conf; 2012 June 4-8; Notre Dame, IN. ASME; 2012. p. 1-9.

[6] Jamshidinia M, Kong F, Kovacevic R. Numerical Modeling of Heat Distribution in the Electron Beam Melting® of Ti-6Al-4V. Journal of Manufacturing Science and Engineering. 2013;135(6):061010.

[7] Sammons PM, Bristow DA, Landers RG. Height Dependent Laser Metal Deposition Process Modeling. Journal of Manufacturing Science and Engineering. 2013;135(5):054501.

[8] Anca A, Fachinotti VD, Escobar-Palafox G, et al. Computational modelling of shaped metal deposition. Int J for Numerical Methods in Eng. 2011;85(1):84-106. 
[9] Chiumenti M, Cervera M, Salmi A, et al. Finite element modeling of multi-pass welding and shaped metal deposition processes. Comput Methods in Appl Mech and Eng. 2010;199(37):2343-2359.

[10] Lundbäck A, Lindgren LE. Modelling of metal deposition. Finite Elements in Analysis and Design. 2011;47(10):1169-1177.

[11] Marimuthu S, Clark D, Allen J, Kamara A, Mativenga P, Li L, et al. Finite Element Modelling of Substrate Thermal Distortion in Direct Laser Additive Manufacture of an Aero-Engine Component. Proceedings of the Institution of Mechanical Engineers, Part C: Journal of Mechanical Engineering Science. 2012;

[12] Mughal M, Fawad H, Mufti R. Three-dimensional finite-element modelling of deformation in weld-based rapid prototyping. Proceedings of the Institution of Mechanical Engineers, Part C: Journal of Mechanical Engineering Science. 2006;220(6):875-885.

[13] Chin R, Beuth J, Amon C. Control of residual thermal stresses in shape deposition manufacturing. In: Proceedings of the Solid Freeform Fabrication Symposium; 1995. p. 221228.

[14] Klingbeil N, Beuth J, Chin R, Amon C. Residual stress-induced warping in direct metal solid freeform fabrication. International Journal of Mechanical Sciences. 2002;44(1):57-77.

[15] Plati A, Tan J, Golosnoy I, Persoons R, Van Acker K, Clyne T. Residual stress generation during laser cladding of steel with a particulate metal matrix composite. Advanced Engineering Materials. 2006;8(7):619-624. 
[16] Denlinger ER, Heigel JC, Michaleris P. Residual stress and distortion modeling of electron beam direct manufacturing Ti-6Al-4V. Proceedings of the Institution of Mechanical Engineers, Part B: Journal of Engineering Manufacture. 2014;p. 0954405414539494.

[17] Francis J, Stone H, Kundu S, Rogge R, Bhadeshia H, Withers P, et al. Transformation temperatures and welding residual stresses in ferritic steels. In: ASME 2007 Pressure Vessels and Piping Conference. American Society of Mechanical Engineers; 2007. p. 949-956.

[18] Dai H, Francis J, Stone H, Bhadeshia H, Withers P. Characterizing phase transformations and their effects on ferritic weld residual stresses with X-rays and neutrons. Metallurgical and Materials Transactions A. 2008;39(13):3070-3078.

[19] Francis J, Bhadeshia H, Withers P. Welding residual stresses in ferritic power plant steels. Materials Science and Technology. 2007;23(9):1009-1020.

[20] Francis J, Turski M, Withers P. Measured residual stress distributions for low and high heat input single weld beads deposited on to SA508 steel. Materials Science and Technology. 2009;25(3):325-334.

[21] Elmer J, Palmer T, Babu S, et al. In situ observations of lattice expansion and transformation rates of $\alpha$ and $\beta$ phases in Ti-6Al-4V. Mater Sci Eng: A. 2005;391(1):104-113.

[22] Denlinger ER, Heigel JC, Michaleris P, Palmer T. Effect of inter-layer dwell time on distortion and residual stress in additive manufacturing of titanium and nickel alloys. Journal of Materials Processing Technology. 2015;215:123-131.

[23] Costa L, Vilar R, Reti T, Deus A. Rapid tooling by laser powder deposition: Process simulation using finite element analysis. Acta Materialia. 2005;53(14):3987-3999. 
[24] Zhang L, Reutzel E, Michaleris P. Finite element modeling discretization requirements for the laser forming process. Int J Mech Sci. 2004;46(4):623-637.

[25] Goldak J, Chakravarti A, Bibby M. A new finite element model for welding heat sources. Metall Trans B. 1984;15(2):299-305.

[26] Benzley SE, Perry E, Merkley K, Clark B, Sjaardama G. A comparison of all hexagonal and all tetrahedral finite element meshes for elastic and elasto-plastic analysis. In: Proceedings, 4th International Meshing Roundtable. vol. 17. Sandia National Laboratories Albuquerque, NM; 1995. p. 179-191.

[27] Inc OE. Revised Thermocouple Reference Tables; 2005. Publication Number z204-206.

[28] Yang J, Sun S, Brandt M, et al. Experimental investigation and 3D finite element prediction of the heat affected zone during laser assisted machining of Ti6Al4V alloy. J Mater Process Technol. 2010;210(15):2215-2222.

[29] Boyer RF, Collings E. In: Materials properties handbook: titanium alloys. ASM international; 1994. p. 514 .

[30] Metals S. Inconel alloy 625; 2006. Publication Number SMC-063.

[31] Michaleris P. Modeling Metal Deposition in Heat Transfer Analyses of Additive Manufacturing Processes. Finite Elem in Analysis and Design. 2014;86:51-60. 